paraplegia and cognitive deficits and the patient was discharged in good conditions on postoperative day 13 .

\section{Discussion}

The multiple pathology in this patient including aortic arch aneurysm, chronic dissection of a distal aortic ascending aneurysm and a rupture of the enlarged descending aorta twenty-six years after traumatic type A aortic dissection with surgical aortic valve repair and proximal ascending aortic replacement posed a tactical and surgical challenge. We decided to replace the entire aorta including the distal ascending aorta, aortic arch and the thoracoabdominal descending aorta in one session ${ }^{1,2}$. Therefore, the patient underwent a single-stage procedure through a thoracoabdominal approach combined with left thoracotomy. In hypothermia we used selective cerebral perfusion and abdominal organ perfusion for organ protection ${ }^{3}$. The patient was discharged without neurological deficits or signs for malperfusion with good liver and kidney function and went back to normal life. The postoperative computed tomography (Figure 2) showed a satisfactory result of the entire aorta after the approach that is described in this report as a useful treatment alternative in patients with these rare combination of diagnoses.

\section{References}

1. Tanaka H, Yamashita T, Okada K, Okita Y. Successful surgery in a patient with a rupture of descending aorta complicated by acute type A aortic dissection through left-sided thoracotomy. Interact CardioVasc Thorac Surg. 2005;4:116-7.

2. Beaver TM, Martin TD. Single-stage transmediastinal replacement of the ascending, arch, and descending aorta. Ann Thorac Surg. 2001;72: $1232-8$.

3. Hagl C, Khaladj N, Karck M, Kallenbach K, Leyh R, Winterhalter M, et al. Hypothermic circulatory arrest during ascending and aortic arch surgery: the theoretical impact of different cerebral perfusion techniques and other methods of cerebral protection. Eur J Cardiothorac Surg. 2003; 24:371-8.

\title{
Persistent severe vasospasm in off-pump coronary artery bypass surgery: The value of intraluminal stenting
}

\author{
Pankaj Saxena, MCh, DNB, Igor E. Konstantinov, MD, PhD, Miriam Koniuszko, MBBS, Tushar Singh, MBBS, \\ and Mark A. J. Newman, FRACS, Perth, Australia
}

T ransient electrocardiographic changes are common after coronary artery bypass surgery and might represent coronary artery or graft vasospasm. The vasospasm often resolves spontaneously or with vasodilators. On rare occasion, however, severe vasospasm persists and might lead to catastrophic events.

From June 1995 through August 2005, 677 off-pump coronary artery bypass grafting (OPCABG) operations were performed in our institution. Two (0.3\%) of these patients had persistent vasospasm.

\section{Clinical Summaries}

PATIENT 1. A 65-year-old man with a history of stable angina was found to have normal right coronary artery and severe left anterior descending artery (LAD) and left circumflex coronary artery stenoses. OPCABG was performed through a median ster-

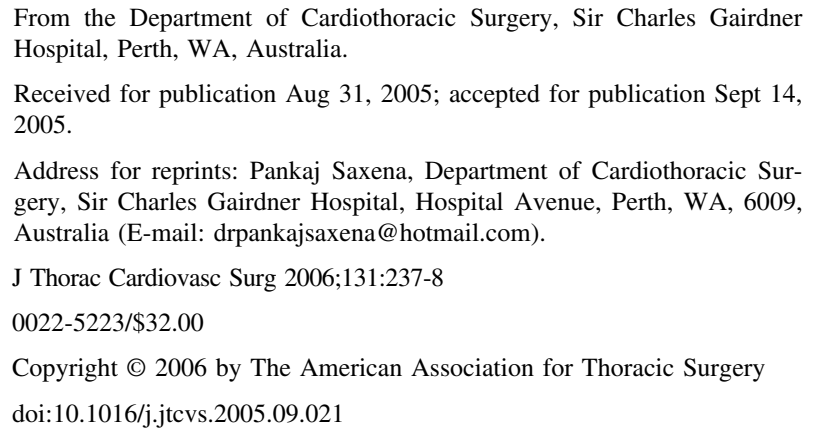

notomy. Snaring of the coronary arteries proximal to anastomosis was done with 3-0 Prolene sutures with Teflon pledgets. An Octopus stabilizer (Medtronic Inc, Minneapolis, Minn) was used. The left internal thoracic artery (LITA) was anastomosed to the $\mathrm{LAD}$, and a saphenous vein graft was anastomosed to the obtuse marginal artery. Two hours after the operation, the patient experienced ischemia in the inferior leads and was started on glyceryl trinitrate (GTN) infusion. An angiogram demonstrated complete occlusion of the right coronary artery, with normal blood flow in other coronary arteries and both grafts. Intracoronary injection of GTN $(500 \mu \mathrm{g})$ and verapamil $(250 \mu \mathrm{g})$ promptly relieved the vasospasm. On postoperative day 1 , however, he experienced ischemia of the anterior left ventricular wall, despite continuous infusions of GTN and verapamil. Repeat angiography demonstrated vasospasm that now involved the LITA and the LAD (Figure 1, A). Intracoronary injection of GTN $(500 \mu \mathrm{g})$, verapamil $(250 \mu \mathrm{g})$, and papaverine $(30 \mathrm{mg})$ failed to relieve the spasm. An intra-aortic balloon pump (IABP) was placed. Balloon angioplasty of the spastic segment was performed, but the effect was short lasting, and vasospasm recurred a few minutes later with ongoing myocardial ischemia. A sirolimus coated Cypher stent (Cordis Corp, Miami Beach, Fla) was placed into the spastic segment of the distal LITA extending through the anastomosis into the LAD (Figure $1, B)$. The patient was discharged home on postoperative day 19.

PATIENT 2. An 84-year-old woman presented with unstable angina and underwent OPCABG with a sequential LITA graft to the diagonal and LAD coronary arteries. Because of postoperative myocardial ischemia, GTN infusion was started, and an IABP was 

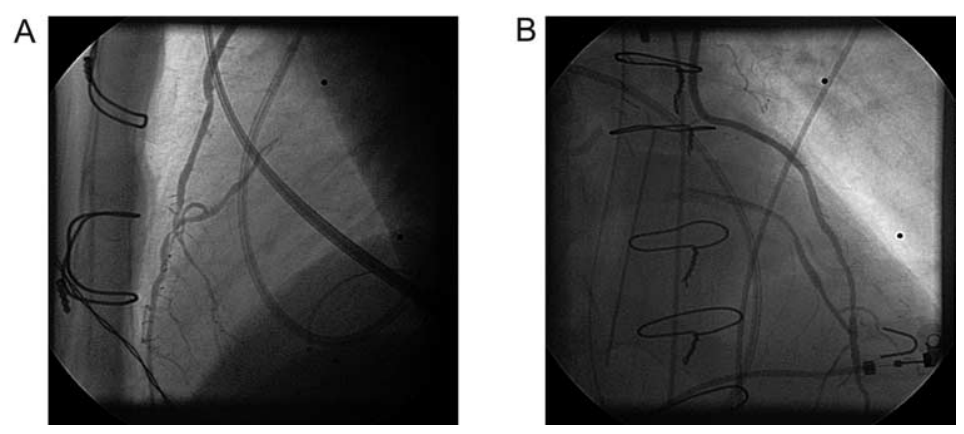

Figure 1. Coronary angiogram before $(A)$ and after (B) stenting of the LITA-to-LAD anastomosis.

inserted. The coronary angiogram demonstrated severe spasm in the segment of the LITA between the diagonal and the LAD anastomosis. The spasm was relieved by means of intracoronary injection of papaverine. We have previously reported this patient in detail. ${ }^{1}$

On the basis of electrocardiographic findings and cardiac enzyme levels, there was no evidence of postoperative myocardial infarction in either patient. Both patients were discharged home on calcium channel blockers and $\beta$-blockers and remained free of angina at 3 months' (patient 1) and 2 years' (patient 2) follow-up.

\section{Discussion}

Persistent coronary artery or graft vasospasm presents a challenging problem that requires immediate and aggressive management. Once postoperative vasospasm is suspected clinically, a prompt coronary angiography should be performed to confirm the diagnosis and to prevent irreversible myocardial damage.

Systemic GTN and IABP is generally effective in patients with ongoing myocardial ischemia; however, both might not be effective in severe vasospasm. ${ }^{2}$ In fact, vasospasm and myocardial ischemia persisted in both of our patients, despite systemic GTN administration and IABP support. Likewise, neither GTN nor IABP relieved persistent coronary and graft vasospasm in the patient reported by Döpfmer and coworkers ${ }^{3}$ after on-pump coronary artery bypass surgery. Their patient required a left ventricular assist device.

The incidence of perioperative coronary artery spasm causing hemodynamic collapse after coronary artery bypass grafting (CABG) with cardiopulmonary bypass was reported to be approx- imately $1 \%,{ }^{2}$ but the incidence of persistent coronary spasm in OPCABG has not been previously reported. The incidence of persistent coronary vasospasm was $0.3 \%$ in our institution. On review of the English-language literature, we found only a few case reports with postoperative coronary spasm in off-pump coronary surgery. ${ }^{4,5}$ We have previously managed persistent vasospasm using intraluminal injection of papaverine. ${ }^{1}$ In the patient described herein, however, the vasospasm persisted despite direct intraluminal injection of the vasodilators and necessitated stenting.

In summary, prompt diagnosis and an aggressive approach is required for the management of this rare and difficult problem. Coronary artery and graft stenting might provide an effective treatment should other options fail.

\section{References}

1. Sanders L, Newman MAJ. Intractable post-operative internal thoracic artery spasm managed with angiographic intraluminal papaverine. J Thorac Cardiovasc Surg. 2005;130:938-40.

2. Buxton AE, Goldberg S, Harken A, Hirshfeld J, Kastor JA. Coronaryartery spasm immediately after myocardial revascularization recognition and management. N Engl J Med. 1981;304:1249-53.

3. Döpfmer UR, Braun JP, Grosse J, Konertz W. Temporary left ventricular assist and levosimendan for coronary artery spasm. Interactive Cardiovasc Thorac Surg. 2005;4:316-8.

4. Bittner HB. Coronary artery spasm and ventricular fibrillation after off-pump coronary surgery. Ann Thorac Surg. 2002;73:297-300.

5. Fukui T, Takanashi S, Hosoda Y. Coronary artery and graft spasm after off-pump coronary artery bypass grafting. Jpn J Thorac Cardiovasc Surg. 2005;53:109-13. 